\title{
Laparoscopic Surgery for Rectal Cancer after Preoperative Chemoradiation in Elderly Patients
}

\author{
Je-Min Choi, M.D., Seung-Hun Lee, M.D., Seung-Hyun Lee, M.D., Byung-Kwon Ahn, M.D. \\ Department of Surgery, Kosin University College of Medicine, Busan, Korea
}

Purpose: Laparoscopic surgery has been accepted as a standard procedure for colorectal cancer. Preoperative chemoradiation for rectal cancer has some advantages, such as decreased tumor size and lower stage, and lower local recurrence. However, preoperative chemoradiation has the disadvantage of increasing postoperative complication risks. The aim of this study was to evaluate the safety of laparoscopic surgery for rectal cancer after preoperative chemoradiation in elderly patients.

Methods: 46 patients underwent laparoscopic surgery for rectal cancer after preoperative chemoradiation. Patients were divided into younger ( $<70$ years, $n=35)$ and older groups $(\geq 70$ years, $\mathrm{n}=11)$.

Results: In the younger group, men were more predominant ( $80 \%$ vs. $54.5 \%, p=0.124)$. In the older group, more patients had high American Society of Anesthesiologists scores (score 3 was 2.9\% vs. $36.4 \%, p=0.005)$ than in the younger group. Sphincter-preserving surgery was performed more frequently in the younger group (77.2\% vs. $45.5 \%, p=0.065)$. Operation time (195.8 min. vs. $212.5 \mathrm{~min}$, $p=0.553)$ and intraoperative blood loss (200.6 cc vs. 209.1 cc, $p=0.952)$ were not significantly different. Significant anastomotic leakage was absent in both groups. Postoperative hospital stay was 9.7 and 10.9 days $(p=0.669)$. Complete remission rates were similar in the both groups $(8.8 \%$ vs. $18.2 \%$, $p=0.824)$.

Conclusion: Postoperative outcomes are comparable between older group and younger group. Laparoscopic surgery could be considered as safe, feasible therapeutic options in elderly patients after preoperative chemoradiation for rectal cancer. However, large randomized trials with comparative methodologies are needed.

Keywords: Laparoscopic surgery, Rectal cancer, Radiation

This is an Open Access article distributed under the terms of the Creative Commons Attribution Non-Commercial License (http:// creativecommons.org/licenses/by-nc/4.0/) which permits unrestricted non-commercial use, distribution, and reproduction in any medium, provided the original work is properly cited.
Received June 27, 2017

Revised 1st August 22, 2017

2nd August 26, 2017

3rd August 30, 2017

Accepted August 31, 2017

Corresponding author

Seung-Hun Lee

Department of Surgery, Kosin

University College of Medicine, 262

Gamcheon-ro, Seo-gu, Busan 49267,

Korea

Tel: +82-51-990-6462

Fax: +82-51-246-6093

E-mail: candoli8182@naver.com

\section{INTRODUCTION}

Preoperative chemoradiation for rectal cancer has some advantages such as decreased tumor size and lower stage and lower local recurrence. The disadvantage of increased postoperative complication risks is debated., ${ }^{1,2}$ Elderly patients have a high incidence of colorectal cancer, which may be associated with increased postoperative morbidity and mortality due to complex comorbidities and diminished cardiopulmonary reserves. Preoperative chemoradiation and old age are considered as risk factors of postoperative complication of rectal cancer patients.

Laparoscopic surgery for colorectal cancer has been accepted as a standard procedure and has become popular. Several studies suggest that laparoscopic surgery for colorectal cancers has benefits over open surgery, including less wound 
pain, earlier recovery, and better cosmetic results, all with similar postoperative outcomes and long-term oncologic results. ${ }^{3-5}$ Several studies show similar overall postoperative complication rates between open surgery and laparoscopic surgery for rectal cancer after preoperative chemoradiation., With advancement of laparoscopic techniques, several studies show that laparoscopic colorectal surgery is a safe and feasible procedure, even in elderly patients. ${ }^{8,9}$

However, the safety of laparoscopic surgery in elderly patients after preoperative chemoradiation is unknown. The aim of this study was to evaluate the safety of laparoscopic surgery for rectal cancer after preoperative chemoradiation in elderly patients.

\section{MATERIALS AND METHODS}

The study protocol was approved by the institutional review board. From a prospectively collected database of all patients undergoing colorectal surgery in our department, 46 consecutive patients were selected who underwent laparoscopic surgery after preoperative chemoradiation for rectal cancer from January 2009 to June 2014. All patients were diagnosed with adenocarcinoma in the rectum with tumors $<15 \mathrm{~cm}$ from the anal verge. Preoperative assessment included digital rectal examination, colonoscopy with biopsy, rectal ultrasound, abdominopelvic computed tomography (CT), chest $\mathrm{x}$-ray, and laboratory data including complete blood cell count, biochemical profiles, serum carcinoembryonic antigen (CEA), and cancer antigen (CA 19-9).

Patients with CTs showing locally advanced tumor (i.e., penetrating through the rectal wall, T3), and/or tumor with lymph node involvement without evidence of distant metastasis were given the option of preoperative chemoradiation therapy. As preoperative chemoradiation therapy, radiation therapy and chemotherapy were administered simultaneously. Radiation was irradiation using a 10-MV linear accelerator from three directions, posterior, right, and left sides, using a wedge. Upper radiation range was up to the fifth lumbar vertebra (L5) or the first sacral vertebra (S1), and laterally, up to the pelvic wall. External iliac lymph nodes were not included in radiation, and special preparation to protect the small intestine was not performed. For radiation doses, $200 \mathrm{cGy}$ per fraction was used once a day, 5 times per week, for total radiation dose 5,000 5,400 cGy. For combined chemotherapy, a combination of $450 \mathrm{mg} / \mathrm{m}^{2} 5$-fluorouracil and $20 \mathrm{mg} / \mathrm{m}^{2}$ leucovorine was infused continuously for 24 hours with initiation of radiation therapy, concomitantly or $1,250 \mathrm{mg} / \mathrm{m}^{2}$ oral capecitabine (Xeloda ${ }^{\circledR}$, Hoffmann-La Roche Ltd., Basel, Switzerland) was administered per day. Surgery was performed an average 8 10 weeks after chemoradiation therapy. All patients underwent mechanical bowel preparation. The laparoscopic surgery program at our department began in 2004.

Patients were divided into a younger group aged younger than 70 years and an older group aged 70 and older. Medical records were retrospectively reviewed for demographics, comorbidity, operation methods, operative time, intraoperative blood loss, postoperative hospital stay, postoperative complications, and pathology results. Operation time was defined as time from initial incision until end of the operation with dressing in place. Operative complications and mortality were defined as complications and death within 30 days of surgery.

SPSS version 17.0 for Windows software (SPSS Inc., Chicago, IL, USA) was used for statistical analysis. Mann Whitney test was used to compare normally distributed variables. Comparisons between groups of discrete variables were made using chi-squared or Fisher's exact tests as appropriate. All $p$ values $<0.05$ were considered statistically significant.

Table 1. Demographics of patients

\begin{tabular}{lccc} 
& $\begin{array}{c}\text { Younger }(<70) \\
(\mathbf{n}=35)\end{array}$ & $\begin{array}{c}\text { Older }(\geq 70) \\
(\mathbf{n}=11)\end{array}$ & $p$ value \\
\hline Age (years) $^{*}$ & $56.3 \pm 7.9$ & $73.1 \pm 2.1$ & $<0.001$ \\
& $(42 \sim 68)$ & $(71 \sim 77)$ &
\end{tabular}

$\begin{array}{lccc}\text { Sex } & & & 0.124 \\ \text { Male } & 28(80.0) & 6(54.5) & \\ \text { Female } & 7(20.0) & 5(45.5) & \\ \text { Body mass index }\left(\mathrm{kg} / \mathrm{m}^{2}\right)^{*} & 23.1 \pm 3.1 & 21.2 \pm 3.4 & 0.189 \\ & (17.4 \sim 29.0) & (14.5 \sim 25.5) & \\ \text { ASA score } & & & 0.005 \\ 1 \sim 2 & 34(97.1) & 7(63.6) & \\ \geq 3 & 1(2.9) & 4(36.4) & \end{array}$

Comobidity

$\begin{array}{llll}\text { Cardiovascular disease } \quad 10(28.6) & 3(27.3) \quad>0.999\end{array}$

Diabetes mellitus $\quad 7(20.0) \quad 2(18.2) \quad>0.999$

$\begin{array}{llll}\text { Smoking } & 15(42.9) & 4(36.4) & >0.999\end{array}$

Concurrent chemotherapy

5-Fluorouracil/Leucovorin $\quad 31$ (88.6) $\quad 9$ (81.8) $\quad 0.619$

Capecitabine $\quad 4(11.4) \quad 2$ (18.2)

Sphincter preserving surgery $\quad 0.065$

\begin{tabular}{lrrr} 
Yes & $27(77.2)$ & $5(45.5)$ & \\
No & $8(22.8)$ & $6(54.5)$ & \\
Protective ileostomy & $13(37.1)$ & $2(18.2)$ & 0.132 \\
\hline
\end{tabular}

*Values are mean (range); other values in parentheses are percentage. 


\section{RESULTS}

Of 46 total patients, 35 were in the younger group less than 70 years; 11 were in the older group aged more than 70 years. Demographics and preoperative variables are in Tables 1 and 2. In the younger group, men were more prominent (80\% vs. $54.5 \%, p=0.124)$. In the older group, more patients had high American Society of Anesthesiologists (ASA) scores ( $\geq 3$ score, $2.9 \%$ vs. $36.4 \%, p=0.005$ ). Mean values for BMI (23.1 vs. 21.2), distance from anal verge $(5.53 \mathrm{~cm}$ vs. $5.45 \mathrm{~cm}$ ), and tumor size $(2.69 \mathrm{~cm}$ vs. $2.46 \mathrm{~cm})$ were similar for the two groups. Sphincter-preserving surgery, such as lower anterior or intersphincteric resection was performed more frequently in the younger group $(77.2 \%$ vs. $45.5 \%, p=0.065)$. Abdominoperineal resection was done in 6 patients in each group (17.1\% vs. 54.5\%). In the younger group with no sphincter preserving surgery, two patients underwent Hartmann's procedure or colostomy. Protective ileostomy was performed on 13 patients (37.1\%) in the younger, and 2 patients (18.2\%) in the older group. Complete remission rate was higher in the older group, but not significantly different (8.8\% vs. $18.2 \%, p=0.824)$. In the older group, two patients (18.2\%) showed pathologically complete response; the two patients underwent abdominoperineal resection (Table 3). Mean distance from the anal verge was $7.6 \mathrm{~cm}$ in patients who underwent sphincter-preserving surgery and $3.6 \mathrm{~cm}$ in patients who underwent abdominoperineal resection in both group. Mean tumor size was $3.2 \mathrm{~cm}$ and $1.8 \mathrm{~cm}$.

Table 2. Clinicopathologic characteristics of rectal cancers

\begin{tabular}{lrrr} 
& $\begin{array}{c}\text { Younger }(<70) \\
(\mathbf{n}=35)\end{array}$ & $\begin{array}{c}\text { Older }(\geq 70) \\
(\mathbf{n}=11)\end{array}$ & $p$ value \\
\hline $\begin{array}{l}\text { Distance from the anal verge } \\
(\mathrm{cm})^{*}\end{array}$ & $\begin{array}{r}5.53 \pm 2.66 \\
(2 \sim 10)\end{array}$ & $\begin{array}{r}5.45 \pm 3.62 \\
(1.5 \sim 12)\end{array}$ & 0.605 \\
\hline $\begin{array}{r}\text { Tumor size }(\mathrm{cm})^{*} \\
2.69 \pm 2.04 \\
(0 \sim 7.0)\end{array}$ & $\begin{array}{r}2.46 \pm 2.32 \\
(0 \sim 6)\end{array}$ & 0.776 \\
Differentiation & & & 0.777 \\
Well-moderate & $30(85.7)$ & $10(90.9)$ & \\
Poor & $2(5.7)$ & 0 & \\
Mucinous & $3(8.6)$ & $1(9.1)$ & \\
Pathologic stage & & & 0.824 \\
$0^{\dagger}$ & $3(8.8)$ & $2(18.2)$ & \\
1 & $10(29.4)$ & $3(27.3)$ & \\
2 & $9(26.5)$ & $2(18.2)$ & \\
3 & $12(35.3)$ & $4(36.4)$ & \\
\hline
\end{tabular}

*Values are mean (range); other values in parentheses are percentage, ${ }^{\dagger}$ complete response.
Operative outcomes and postoperative complications are in Tables 4, 5. Operation time (195.8 $\mathrm{min}$ vs. $212.5 \mathrm{~min} p=0.553$ ) and intraoperative blood loss (200.6 cc vs. $209.1 \mathrm{cc}, p=0.952$ ) were not significantly different. Anastomotic leakage was absent in both groups. Postoperative hospital stay was 9.7 and 10.9 days $(p=0.669)$.

\section{DISCUSSION}

The incidence of colorectal cancer in older patients is likely to increase with an aging population. With average life expectancy becomes longer, colorectal surgery in older patients occurs more frequently. However, older patients may have complex comorbidities and diminished cardiopulmonary reserves, which are associated with increased morbidity and mortality from colorectal surgery. ${ }^{10,11}$

Laparoscopic colorectal surgery has become more prevalent worldwide. Several studies have suggested that laparoscopic surgery for colorectal cancer may have some benefits such as less wound pain, earlier recovery, and better cosmetic results, with similar postoperative outcomes to open surgery. ${ }^{3-5} \mathrm{How}^{-}$ ever, laparoscopic surgery requires pneumoperitoneum with carbon dioxide gas, which may reduce venous return, diminish cardiac output and cause hypercarbia. This procedure should be used selectively in older patients with limited cardiopulmonary reserves. Several studies report that, with advancement of anesthetic and surgical techniques, laparoscopic colorectal

Table 3. Demographics of patients underwent APR

\begin{tabular}{|c|c|c|c|}
\hline & $\begin{array}{l}\text { Younger }(<70) \\
\quad(n=6)\end{array}$ & $\begin{array}{c}\text { Older }(\geq 70) \\
\quad(n=6)\end{array}$ & $p$ value \\
\hline Age (years) ${ }^{*}$ & $\begin{array}{l}55.3 \pm 8.66 \\
(44 \sim 68)\end{array}$ & $\begin{array}{c}73.8 \pm 2.04 \\
(71 \sim 77)\end{array}$ & 0.010 \\
\hline Male & $5(83.3)$ & $2(33.3)$ & 0.242 \\
\hline Body mass index $\left(\mathrm{kg} / \mathrm{m}^{2}\right)^{*}$ & $\begin{array}{c}20.8 \pm 2.68 \\
(17.4 \sim 24.1)\end{array}$ & $\begin{array}{c}21.5 \pm 4.49 \\
(14.5 \sim 25.5)\end{array}$ & 0.111 \\
\hline ASA score $(\geq 3)$ & 0 & $2(33.3)$ & 0.211 \\
\hline Comobidity (diabetes mellitus) & 0 & $1(16.7)$ & $>0.999$ \\
\hline Smoking & $4(66.7)$ & $2(33.3)$ & 0.567 \\
\hline $\begin{array}{l}\text { Distance from the anal verge } \\
(\mathrm{cm})^{*}\end{array}$ & $\begin{array}{r}4.33 \pm 3.27 \\
(2 \sim 5.4)\end{array}$ & $\begin{array}{l}3.67 \pm 2.75 \\
(1.5 \sim 6)\end{array}$ & 0.432 \\
\hline Tumor size $(\mathrm{cm})^{*}$ & $\begin{array}{c}1.91 \pm 1.80 \\
(0 \sim 5)\end{array}$ & $\begin{array}{c}1.86 \pm 2.72 \\
(0 \sim 6)\end{array}$ & 0.207 \\
\hline Complete response & 0 & 2 (33.3) & 0.300 \\
\hline
\end{tabular}

*Values are mean (range); other values in parentheses are percentage, $\mathrm{APR}=$ abdominoperineal resection. 
Table 4. Operative outcomes

\begin{tabular}{lccc}
\hline & $\begin{array}{c}\text { Younger }(<70) \\
(\mathbf{n}=35)\end{array}$ & $\begin{array}{c}\text { Older }(\geq 70) \\
(\mathbf{n}=11)\end{array}$ & $p$ value \\
\hline Operative time $(\mathrm{min})^{*}$ & $\begin{array}{c}195.9 \pm 66.41 \\
(140.0 \sim 380.0)\end{array}$ & $\begin{array}{c}215.5 \pm 84.01 \\
(120.0 \sim 320.0)\end{array}$ & 0.553 \\
& $200.6 \pm 188.26$ & $209.1 \pm 205.93$ & 0.952 \\
Blood loss (cc) & $(50 \sim 1,000)$ & $(50 \sim 800)$ & \\
& $9.7 \pm 4.11$ & $10.9 \pm 5.38$ & 0.669 \\
Postoperative hospital & $(4 \sim 26)$ & $(6 \sim 26)$ & \\
stay (days) & $11.3 \pm 6.76$ & $13.7 \pm 6.63$ & 0.496 \\
Sampled lymph node & $(0 \sim 30)$ & $(0 \sim 25)$ & \\
& & &
\end{tabular}

surgery in older patients is a safe and feasible procedure. ${ }^{8,9}$ Bottino et al. ${ }^{8}$ compared postoperative outcomes in two groups divided according to the age of 75 years. Conversion rate to open surgery was the same between the two groups. Postoperative complication rates were also the same but with increased in cardiopulmonary complications in older patients. No mortality occurred. Jeong et al. ${ }^{9}$ compared short-term outcomes in patients who were $\geq 75$ years $(n=92)$ and 75 ( $n=824)$. They reported that higher overall complication rate in patients $\geq 75$ years $(12.0 \%$ vs. $6.2 \%, p=0.047)$. However, clinically significant complications were not different between the two groups. This result suggests that laparoscopic colorectal surgery in older patients is safe and feasible. Fiscon et al. ${ }^{12}$ compared postoperative outcomes between matched two groups of people $\geq 75$ years $(n=50)$ and $75(n=50)$. The study showed more postoperative complications in older patients, even when matched by ASA score and type of operation. They suggested that in older patients, laparoscopic colorectal surgery should be performed by experienced surgeons in specialized centers.

Compared to younger groups, the incidence of postoperative complications increases in older groups undergoing laparoscopic colorectal surgery. In an aging population, comparing between open surgery and laparoscopic surgery, laparoscopic colorectal surgery has advantages in postoperative complications, time to return of normal bowel function, and duration of hospital stay ${ }^{13,14}$ Vallribera et al. ${ }^{14}$ compared morbidity and mortality between open and laparoscopic surgery groups in older people $\geq 75$ years. They reported a lower overall complication rate ( 37.3 vs. $21.6 \%, p=0.001$ ) with fewer surgical site infections in the laparoscopic surgery group. Mortality was also lower (6.7\% vs. 3.2\%, $p=0.034)$ and duration of hospital stay was shorter (11.4 days vs. 7.8 days).

Rectal surgery is more challenging for surgeons than colon surgery. Surgeons have to consider the narrow pelvic cavity, nerve preservation, sphincter saving and radiation effects in rectal surgery. Preoperative chemoradiation for rectal cancer
Table 5. Postoperative complications

\begin{tabular}{lccc}
\hline & $\begin{array}{c}\text { Younger }(<70) \\
(\mathbf{n}=35)\end{array}$ & $\begin{array}{c}\text { Older }(\geq 70) \\
(\mathbf{n}=11)\end{array}$ & $p$ value \\
\hline Total & $7(20.0)$ & $1(9.1)$ & 0.405 \\
Wound seroma & $1(2.9)$ & 0 & 0.571 \\
\hline Anastomotic leakage & 0 & 0 & \\
Chyle leakage & $2(5.7)$ & 0 & 0.418 \\
Ileus & $3(8.6)$ & 0 & 0.315 \\
\hline Bladder dysfunction & 0 & $1(9.1)$ & 0.071 \\
\hline Pneumonia & $1(2.9)$ & 0 & 0.571 \\
\hline
\end{tabular}

is a known significant risk factor for anastomotic leakage in open and laparoscopic surgery. ${ }^{15,16}$ Park et al. ${ }^{16}$ assessed the risk factors for clinical anastomotic leakage in patients undergoing laparoscopic surgery for rectal cancer. In patients without defunctioning stoma, anastomotic leakage percentages were $6.1 \%$ vs. $16.2 \%$ according to use of preoperative chemoradiation $(p=0.001)$ in univariable and multivariable analysis. In the study, anastomotic leakage was not significantly different $(5.4 \%$ vs. $7.3 \%, p=0.326$ ) for age $\geq 75$ or $<75$ years.

Our study focused on older patients ( $\geq 70$ years) who underwent laparoscopic surgery for rectal cancer after preoperative chemoradiation. $^{17-19}$ In the older group, patients with high ASA scores ( $\geq 3$ score, $2.9 \%$ vs. $36.4 \%, p=0.005$ ) were prominent. Sphincter-preserving surgery such as lower anterior resection and intersphincteric resection was done in the younger group more frequently than the older group (77.2\% vs. $45.5 \%$, $p=0.065$ ). Also, protective ileostomy was more frequent in the younger group. We may consider abdominoperineal resection more frequently in an older group with poor anal sphincter tone. In two patients with complete response to preoperative chemoradiation, both underwent abdominoperineal resection (Table 3). For anastomotic leakage, mortality did not occur in the both groups. However, this study has some limitations, such as small numbers of patient, retrospective, not matched, not randomized.

In conclusion, even in elderly patients after preoperative chemoradiation for rectal cancer, postoperative outcomes of laparoscopic surgery and open surgery was not different significantly. Laparoscopic surgery could be considered as a safe, feasible therapeutic option in elderly patients after chemoradiation. However, large randomized trials with comparative methodology are needed.

\section{REFERENCES}

1) Marijnen CA, Kapiteijn E, van de Velde CJ, et al. Acute side 
effects and complications after short-term preoperative radiotherapy combined with total mesorectal excision in primary rectal cancer: report of a multicenter randomized trial. J Clin Oncol 2002;20:817-825.

2) Holm T, Singnomklao T, Rutqvist LE, Cedermark B. Adjuvant preoperative radiotherapy in patients with rectal carcinoma. Adverse effects during long term follow-up of two randomized trials. Cancer 1996;78:968-976.

3) Clinical Outcomes of Surgical Therapy Study Group, Nelson H, Sargent DJ, et al. A comparison of laparoscopically assisted and open colectomy for colon cancer. N Engl J Med 2004;350:20502059.

4) Veldkamp R, Kuhry E, Hop WC, et al. Laparoscopic surgery versus open surgery for colon cancer: short-term outcomes of a randomised trial. Lancet Oncol 2005;6:477-484.

5) Guillou PJ, Quirke P, Thorpe H, et al. Short-term endpoints of conventional versus laparoscopic-assisted surgery in patients with colorectal cancer (MRC CLASICC trial): multicentre, randomised controlled trial. Lancet 2005;365:1718-1726.

6) Kang SB, Park JW, Jeong SY, et al. Open versus laparoscopic surgery for mid or low rectal cancer after neoadjuvant chemoradiotherapy (COREAN trial): short-term outcomes of an open-label randomised controlled trial. Lancet Oncol 2010;11:637-645.

7) Ishihara $S$, Watanabe T, Fukushima $Y$, et al. Safety and factors contributing to the difficulty of laparoscopic surgery for rectal cancer treated with preoperative chemoradiotherapy. Tech Coloproctol 2014;18:247-255.

8) Bottino V, Esposito MG, Mottola A, et al. Early outcomes of colon laparoscopic resection in the elderly patients compared with the younger. BMC Surg 2012;12 Suppl 1:S8.

9) Jeong DH, Hur H, Min BS, Baik SH, Kim NK. Safety and feasibility of a laparoscopic colorectal cancer resection in elderly patients. Ann Coloproctol 2013;29:22-27.
10) Al-Refaie WB, Parsons HM, Habermann EB, et al. Operative outcomes beyond 30-day mortality: colorectal cancer surgery in oldest old. Ann Surg 2011;253:947-952.

11) Tan KK, Koh FH, Tan YY, Liu JZ, Sim R. Long-term outcome following surgery for colorectal cancers in octogenarians: a single institution's experience of 204 patients. J Gastrointest Surg 2012;16:1029-1036.

12) Fiscon V, Portale G, Frigo F, Migliorini G. Laparoscopic resection of colorectal cancer: matched comparison in elderly and younger patients. Tech Coloproctol 2010;14:323-327.

13) Grailey K, Markar SR, Karthikesalingam A, Aboud R, Ziprin P, Faiz O. Laparoscopic versus open colorectal resection in the elderly population. Surg Endosc 2013;27:19-30.

14) Vallribera Valls F, Landi F, Espin Basany E, et al. Laparoscopyassisted versus open colectomy for treatment of colon cancer in the elderly: morbidity and mortality outcomes in 545 patients. Surg Endosc 2014;28:3373-3378.

15) Lee WS, Yun SH, Roh YN, et al. Risk factors and clinical outcome for anastomotic leakage after total mesorectal excision for rectal cancer. World J Surg 2008;32:1124-1129.

16) Park JS, Choi GS, Kim SH, et al. Multicenter analysis of risk factors for anastomotic leakage after laparoscopic rectal cancer excision: the Korean laparoscopic colorectal surgery study group. Ann Surg 2013;257:665-671.

17) Law WL, Chu KW, Tung PH. Laparoscopic colorectal resection: a safe option for elderly patients. J Am Coll Surg 2002;195:768-773.

18) Frasson M, Braga M, Vignali A, Zuliani W, Di Carlo V. Benefits of laparoscopic colorectal resection are more pronounced in elderly patients. Dis Colon Rectum 2008;51:296-300.

19) Gultekin FA, Wong MT, Podevin J, et al. Safety of laparoscopic ventral rectopexy in the elderly: results from a nationwide database. Dis Colon Rectum 2015;58:339-343. 